\title{
Phase Change Materials (PCM) Microcapsules with Different Shell Compositions: Preparation, Characterization and Thermal Stability
}

L. Bayés-García, L. Ventolà, R. Cordobilla, R. Benages, T. Calvet, M.A. Cuevas-Diarte

Departament de Cristal-lografia, Mineralogia i Dipòsits Minerals, Facultat de Geologia, Universitat de Barcelona, Martí i Franquès s/n, E-08028 Barcelona, Spain

\begin{tabular}{|c|c|}
\hline Corresponding author: & laurabayes@ub.edu \\
\hline & Martí i Franquès s/n \\
\hline & E-08028 Barcelona \\
\hline & Spain \\
\hline & Tel. +34 934021350 \\
\hline & Fax. +34 934021340 \\
\hline
\end{tabular}

\section{ABSTRACT}

In this study, Phase Change Materials (Rubitherm® RT 27) microcapsules were successfully obtained by two different methods. The main difference between them remains on the shell composition, as they are composed by different coacervates (Sterilized Gelatine/Arabic Gum for the SG/AG method and Agar-Agar/ Arabic Gum for the AA/AG method). Microcapsules were thermally characterized by ThermoOptical Microscopy and Differential Scanning Calorimetry. Using Scanning Electron Microscopy, their spherical morphology (sphericity factor of 0.94-0.95) and their particle size distribution were determined, obtaining an average diameter of $12 \mu \mathrm{m}$ for the SG/AG method and lower values for the AA/AG method, where nanocapsules were also observed (average diameter of $4.3 \mu \mathrm{m}$ for the microcapsules and $104 \mathrm{~nm}$ for the nanocapsules). The thermal stability determination was carried out by Thermogravimetric analyses (TG) and the results show a high decomposition temperature, although the process takes places in four steps for the two mentioned methods. Moreover, the microcapsules obtained by the AA/AG method decompose in a more gradual way, as in the TG results a double step, instead of one, is appreciable. On the whole, the prepared microencapsulated PCM are totally capable of developing their role in thermal energy storage. 


\section{KEY WORDS}

Thermal Energy Storage, Microencapsulation, Phase Change Material, Coacervation.

\section{Introduction}

The PCM (Phase Change Materials) application in energy storage is well-known in many fields [1-3], because of their great capacity to absorb and slowly release the latent heat involved in a phase change process. Phase Change Materials can be used in order to increase the thermal mass of buildings [4-6] and even clothing (fabric uses) [7-9] without greatly affecting their actual mass. $\mathrm{N}$-alkanes, their mixtures and paraffin waxes have been proposed as Phase Change Materials [10].

One problem to solve in some PCM applications is the liquid migration. Therefore, some kinds of packing are used. Microcapsules consist of little containers, which pack a core material with a hard shell. Standard microencapsulation processes need hydrophobic core materials, so paraffin waxes become so appropriate to develop this role [11]. Microencapsulating PCM brings us some important advantages like that microcapsules can handle Phase Change Materials as core, as they tolerate volume changes; there is a reduction of the reactivity of the paraffin wax with the outside environment; it increases the heat-transfer area and the handling and manipulation of paraffins becomes easier.

Microencapsulation can take place by a physical (spray-drying [12, 13], coating processes [14], etc.) or chemical process (coacervation with gelatine $[12,15]$, interfacial polymerization techniques [8, 16-18], etc.). Moreover, there are different compounds capable of becoming shell materials. A typical microencapsulation process is the one which uses formaldehyde resins, like urea-formaldehyde resins [7, 19, 20] and melamine-formaldehyde resins [21-25]. However, some of the residues of these microencapsulation processes can cause environmental and health problems. As an alternative to this problem, Hawlader et al. [12] used gelatine and Arabic gum in order to encapsulate paraffin. A recent work [26] focuses on the permeability, morphology, thickness of the wall and also on ways of obtaining a more compact one. Mechanical properties of microcapsules have to be determined [7, 20, 23, 24], as they can develop an important role depending on the final application of the product. At this point, there is a need of a more simplified and accurate method to determine these 
properties. Moreover, obtaining microcapsules with higher thermal stability and physical strength becomes important, especially for textile products [27].

In this study, we have developed three different microencapsulation methods, whose residues become totally inert: agar-agar, Arabic gum and gelatine. Several efforts were made in order to obtain microcapsules and the final procedures become the result of an optimization (using lower temperatures, working with diluted components instead of powder, etc.). In this sense, we observed that if the main stirring process took place in an ultrasound bath, the microcapsules size became more uniform (the size distribution was narrower) than if the stirring was mechanically developed.

\section{Materials and Methods}

\subsection{Materials}

Powder food grade gelatine and spray-dried Arabic gum were both purchased from Merck. Agar-agar (for microbiology use) was obtained from Fluka. Analytical grade diethyl ether and distilled water were also used. The PCM (Phase Change Material) was purchased from Rubitherm (Rubitherm® RT 27) and it is made by a mixture of solid saturated hydrocarbons with the molecular formula $\mathrm{C}_{\mathrm{n}} \mathrm{H}_{2 \mathrm{n}+2}\left(4 \% \mathrm{C}_{17} \mathrm{H}_{32} ; 45 \% \mathrm{C}_{18} \mathrm{H}_{34}\right.$; $36 \% \mathrm{C}_{19} \mathrm{H}_{36} ; 12 \% \mathrm{C}_{20} \mathrm{H}_{38} ; 2 \% \mathrm{C}_{21} \mathrm{H}_{40}$ and $1 \%$ other alkanes). The main physicochemical parameters of PCM RT 27, which are given by Rubitherm ${ }^{\circledR}$ [28], are the melting point of about 298-301 K (25-28 C), heat storage capacity of $184 \mathrm{~J} \cdot \mathrm{g}^{-1}$, volume expansion in phase change range of $16 \%$ and flash point at about $437 \mathrm{~K}\left(164^{\circ} \mathrm{C}\right)$.

\subsection{Methods}

\subsubsection{Preparation of PCM microcapsules}

Three different microencapsulation methods were carried out. All of them involve the use of more than one colloid and follow the coacervation technique. A coacervate was used as wall material and it was composed of Arabic gum (AG) (because of its capacity to form films) and gelatine (G) or agar-agar (AA). In a first method to obtain microcapsules (G/AG method), powder food grade gelatine was used, but it favoured microorganism growth, so it was substituted by sterilized gelatine (SG/AG Method) and 
agar-agar, which is also a gel developer (AA/AG method). With the two last mentioned methods, microorganism growth was avoided.

\section{G/AG Method: Gelatine/Arabic gum as shell material}

Firstly, approximately $3 \mathrm{~g}$ of powder food grade gelatine was mechanically stirred at room temperature in $27 \mathrm{ml}$ of distilled water (solution of $10 \% \mathrm{w} / \mathrm{w}$ ) until a gelatinous texture was obtained. Afterwards, it was introduced in an ultrasound bath at $65^{\circ} \mathrm{C}$ and $11 \mathrm{~g}$ of Rubitherm® RT 27 were added, maintaining the conditions for 25 minutes. Then, an Arabic gum solution of $10 \% \mathrm{w} / \mathrm{w}$ (obtained by mechanically stirring $5 \mathrm{~g}$ of spray-dried Arabic gum in $45 \mathrm{ml}$ of distilled water at room temperature) was slowly added (not necessarily drop-by-drop) and ultrasonic power and temperature were maintained for two hours. The preparation of PCM microcapsules was finished after mechanical stirring for about twenty hours at room temperature.

Isolation of PCM microcapsules from the matrix: Diethyl ether was added to the product in a ratio 1:5 in order to dissolve the matrix. The mix was vigorously shaken by hand and centrifuged (Hettich Zentrifugen ROTOFIX $32 \mathrm{~A}$ ) at $2000 \mathrm{rpm}$ for 30 minutes. Engine speeds and length of the centrifugation become the result of an optimization process, obtaining an appropriate isolation without damaging the microcapsules, in other words, performing a useful and non-aggressive procedure.

\section{SG/AG Method: Sterilized gelatine/Arabic gum as shell material}

A mix of powder gelatine and distilled water $(10 \% \mathrm{w} / \mathrm{w})$ was sterilized in an autoclave (SELECTA, model Autotester-E) for 20 minutes at $394 \mathrm{~K}$ and under $1.013 * 10^{5}$ Pa over normal pressure. For the microcapsules synthesis, $30 \mathrm{ml}$ of the sterilized gelatine solution was taken.

Isolation of PCM microcapsules from the matrix: Diethyl ether was added in a ratio 1:5. After shaking by hand the resulting mix was centrifuged for 45 minutes at $2000 \mathrm{rpm}$. Diethyl ether and distilled water were added to the top phase and centrifuged 25 minutes more at $2000 \mathrm{rpm}$. Finally, the same solvents were added again and centrifuged for a further 25 minutes at $2000 \mathrm{rpm}$. 


\section{AA/AG Method: Agar-agar/Arabic gum as shell material}

In this method, the $10 \%$ w/w gelatine solution of the G/AG method was substituted by a $3 \% \mathrm{w} / \mathrm{w}$ agar-agar solution, so approximately $0.83 \mathrm{~g}$ of agar-agar were dissolved in 27 $\mathrm{ml}$ of distilled water, by mechanical stirring at $50^{\circ} \mathrm{C}$.

Isolation of PCM microcapsules from the matrix: Diethyl ether was added in a ratio 1:5 in order to dissolve the matrix. The sample was shaken by hand and centrifuged at 2000 rpm for 45 minutes. The top phase, which contained the microcapsules, was removed and diethyl ether and distilled water were added (1:5 and 2:5 respectively). The mix was centrifuged again for 25 minutes.

\subsubsection{Characterization of microcapsules}

\section{Differential Scanning Calorimetry (DSC)}

The energy storage capacity of the PCM contained in the microcapsules was measured with a Perkin-Elmer DSC-7 calorimeter. Samples (3.9-4.3 mg) were weighted into $50 \mu \mathrm{l}$ aluminium pans and covers were sealed into place. The instrument was calibrated by reference to the enthalpy and melting point of indium (melting temperature: $429.6 \mathrm{~K}$; $\Delta \mathrm{H}_{\mathrm{f}}: 28.45 \mathrm{~J} \cdot \mathrm{g}^{-1}$ ) and decane (melting temperature: $243.3 \mathrm{~K} ; \Delta \mathrm{H}_{\mathrm{f}}: 202.1 \mathrm{~J} \cdot \mathrm{g}^{-1}$ ) standards. An empty pan was used as reference. Dry nitrogen was used as purge gas in the DSC cell at $36 \mathrm{~cm}^{3} \cdot \mathrm{min}^{-1}$. Thermograms were analyzed with Pyris Series Software to obtain enthalpy $\left(\mathrm{J} \cdot \mathrm{g}^{-1}\right)$ (integration of the DSC signals), $\mathrm{T}_{\text {onset }}(\mathrm{K})$ and $\mathrm{T}_{\text {end }}(\mathrm{K})$ of the transitions (intersection of the baseline and the initial and final tangent at the transition). Samples were heated at a constant rate of $2 \mathrm{~K} \cdot \mathrm{min}^{-1}$, from $273 \mathrm{~K}$ to $313 \mathrm{~K}$, until the liquid phase of PCM was observed. Four independent measurements were made for each sample $(n=4)$. The random part of the uncertainties was estimated with a $95 \%$ threshold of reliability using Student's Method, which enables estimating the mean of a normally distributed population when the sample size is small.

\section{Scanning Electron Microscopy (SEM)}

SEM analyses were performed at room temperature on a Hitachi S-4100 Field-Emission apparatus. The microcapsules were mounted on a support platform (12-mm diameter) with a conductor adhesive (Agar Scientific) and fixed with a thin carbon layer (ca. 20 $\mathrm{nm})$. 


\section{Thermo-Optical Microscopy (TOM)}

TOM Images were obtained on a Linkam THMSG-600 stage mounted to a Nikon Eclipse 50iPol Microscope. The sample was placed on a 7-mm quartz-cover slip, and encased within a pure Ag lid so that it was heated from all sides, ensuring a uniform temperature. A LNP liquid nitrogen cooling system and a TMS94 temperature controller were used. Images were captured with a Nikon Digital Camera DXM1200F and the NIS-Elements Software.

\section{Thermogravimetric Analysis (TG)}

Thermogravimetric analyses were carried out on a thermal analyzer Perkin Elmer TG7. The instrument was calibrated with calcium oxalate from 323 to $873^{\circ} \mathrm{C}$ at a heating rate of $10 \mathrm{~K} \cdot \mathrm{min}^{-1}$ in an inert atmosphere $\left(\mathrm{N}_{2}\right)$.

\section{Particle size determination}

Particle sizes and sphericity factors were determined with the IMAT Software (developed by the Technical Scientific Services of the University of Barcelona). The sphericity factor is a parameter which permits knowing how round the microcapsules are. The IMAT Software obtains it by calculating the ratio between the minor and major axes of microcapsules. Therefore, when the number is close to unity then it can be suggested the microcapsule is spherical.

\section{Results and discussion}

Microcapsules were successfully prepared by the three methods: using gelatine, sterilized gelatine and agar-agar (where nanocapsules were also obtained). The microcapsules morphology was determined by Field-Emission Scanning Electron Microscopy. Figure 1 shows some FE-SEM images of the microcapsules obtained.

(Figure 1)

It can be observed that all microcapsules have spherical shape and, especially the ones synthesized by the AA/AG method, have smooth and compact surfaces. By this method, also nanocapsules were obtained (Figure 1c): in this case, before putting the sample on the FE-SEM stub, it was subjected to a freeze-drying process on a brass sheet. 
Thermo-Optical Microscopy experiments confirmed (for the three methods) that the microencapsulation of Rubitherm ${ }^{\circledR}$ RT 27 had been achieved, so that this PCM was included inside the microcapsules. When cooling the microcapsules and lower temperatures than the corresponding to the PCM's crystallization are reached, the microcapsules' shape gets adapted to the solidified PCM. As an example, Figure 2 shows several TOM images of the microcapsules obtained by the G/AG method. Each image was taken at a different temperature.

(Figure 2)

In Figure 3, the microcapsule size distribution, for the ones obtained by the G/AG method, is represented. Diameters are included in the range of 1-45 $\mu \mathrm{m}$. The average diameter is about $9 \mu \mathrm{m}$, with a sphericity factor of 0.95 .

(Figure 3)

However, after about one month storing these isolated microcapsules at room temperature, one could observe some microorganism growth in the sample. This fact could be due to the composition of the powder food grade gelatine, which contains less than $1000 \mathrm{CFU} / \mathrm{g}$ and, in the laboratory, the conditions that allow this microorganism growth could take place. Obviously, this microbial growth would become a great inconvenient, due to the final application of microcapsules, like their use as an impregnation for thermal protection in buildings. One possible alternative to avoid this proliferation was the use of sterilized gelatine (directly obtained as a commercial product or by sterilizing the gelatine in an autoclave). That was the reason why in this study, in the SG/AG microencapsulation method, sterilized gelatine was used as a substitute of gelatine in order to prevent the sample from this degradation.

If the gelatine was sterilized, microcapsules were also formed and, after some storage time (approximately 2 months), there was no microorganism growth.

Figure 4 shows the particle size distribution. The average diameter for this method is 12 $\mu \mathrm{m}$ with a sphericity factor of 0.94 . The whole range goes from $3 \mu \mathrm{m}$ until $45 \mu \mathrm{m}$.

(Figure 4) 
Finally, in order to avoid the inconvenience of having to sterilize gelatine and, therefore, optimizing the procedure, a third method was performed using agar-agar instead of sterilized gelatine. Several months after the performance of the AA/AG method, it was also checked that microorganism growth was also avoided if agar-agar was used.

For this last case, particle size distribution is represented in Figure 5. Microcapsules diameters are included in the range $0.5-17 \mu \mathrm{m}$. The average diameter is $4.3 \mu \mathrm{m}$, with a sphericity factor of 0.94 . In the whole range, it is noticeable the presence of nanocapsules, also appreciable in Figure 1.

(Figure 5)

Figure 6 shows the particle size distribution of the nanocapsules before mentioned. A diameter range of 80-145 $\mathrm{nm}$ was obtained, with an average diameter of $104 \mathrm{~nm}$. The sphericity factor was about 0.95 .

(Figure 6)

Differential Scanning Calorimetry experiments were carried out (shown in Figure 7). In Table 1, values of $\mathrm{T}_{\text {onset }}, \mathrm{T}_{\text {end }}$ and Enthalpy for the melting process of the PCM (Rubitherm ${ }^{\circledR}$ RT 27) are presented. Shape factors are about the same magnitude than for pure alkanes [29]: this fact could become an indicative that the PCM is an alloy, instead of a mixture of alkanes.

(Table 1)

The important enthalpy error values have to be emphasized. This fact is due to the nature of the commercial product (PCM), as it might have a low purity level. Obviously, values of enthalpy for the encapsulated PCM become lower than for the free one, as in the same amount of sample there are other components. Referring to the encapsulated PCM, with both methods (sterilized gelatine and agar-agar) the same enthalpy values are obtained. 
(Figure 7)

The encapsulation ratio of RT 27 was calculated by the way of the enthalpy values of microcapsules containing PCM $\left(\Delta \mathrm{H}_{\mathrm{MEPCM}}\right)$ and the enthalpy of the PCM itself $\left(\Delta \mathrm{H}_{\mathrm{PCM}}\right)$, following the equation [30]:

$\mathrm{PCM}(\mathrm{wt} \%)=\left(\Delta \mathrm{H}_{\mathrm{MEPCM}} / \Delta \mathrm{H}_{\mathrm{PCM}}\right) \cdot 100$

Encapsulation ratios for the SG/AG and $\mathrm{AA} / \mathrm{AG}$ methods were $49 \%$ and $48 \%$, respectively, which become quite low if they are compared to the BASF microencapsulation ratio [31], but high with respect to other studies [30]. Further work will be necessary in order to increase this ratio, as developing a high-performance process becomes interesting.

Thermal stability of microcapsules (SG/AG and AA/AG methods) was evaluated by TG and compared with the stability of free PCM (see Figure 8 and Table 2).

(Figure 8)

(Table 2)

Free PCM is stable until its decomposition (according to the commercial data, the flash point of Rubitherm ${ }^{\circledR}$ RT 27 is about $437 \mathrm{~K}$ ). This PCM decomposition could probably be the responsible for the microcapsules break (step 4 for the SG/AG method and step 2 for the AA/AG method). This fact was deduced from the comparison between the DTG of the free PCM and the microencapsulated one. The great difference between both microencapsulation methods could remain on the fact that for the SG/AG method, both microcapsules break and components decomposition take place at the same time and for the case of the AA/AG method, the microcapsules degradation occurs in a more gradual way: in the TG curve there is a double step (from 415.5 to $504.7 \mathrm{~K}$ and from 504.7 to $577.6 \mathrm{~K}$ ) that could probably represent that firstly the microcapsules break and, afterwards, the resultant components decompose. Perhaps, such a gradual decomposition could become the consequence of a more resistant shell. 


\section{Conclusions}

PCM was successfully microencapsulated by two different methods (SG/AG and $\mathrm{AA} / \mathrm{AG})$. Based on the DSC results, it was possible to compare the temperatures and latent heats of the melting process for the free PCM and the microencapsulated one (obtaining the same enthalpy values for the SG/AG and AA/AG methods). The encapsulation ratio was also determined and it became very similar in both cases (49 and $48 \%$, respectively). Thermo-Optical Microscopy experiments confirmed that the PCM was contained inside the microcapsules and there was a correlation with the DSC results. Scanning Electron Microscopy analyses permitted the study of the microcapsules morphology and particle size. In this sense, microcapsules obtained by the AA/AG method become smaller (also obtaining nanocapsules). Referring to the TG results, in both methods the decomposition takes place at so high temperatures. On the whole, the prepared microencapsulated PCM are totally capable of developing their role in thermal energy storage.

\section{ACKNOWLEDGEMENTS}

We would like to thank Eva Prats Miralles of the Technical Scientific Services of the University of Barcelona for all her help in the sample preparations in order to obtain Scanning Electron Microscopy images. We are also very grateful to $\mathrm{M}^{\mathrm{a}}$ Mercedes Berlanga Herranz of the Microbiology Department of the Faculty of Pharmacy of the University of Barcelona for all her explanations and interpretations when microorganism growth took place in the microcapsules. Finally, we also thank the Ministerio de Ciencia y Tecnologia for the financial support through the CICYT (Project $n^{\circ}$ MAT2008-00497/NAN), the Generalitat de Catalunya through the Grup Consolidat (SGR 2009 1307), the Xarxa de Referencia R+D+I en Materials Avançats per l'Energia (XaRMAE) and the Ministerio de Educación y Ciencia through la Factoría Cristalográfica (Consolider-Ingenio 2010, No. CSD2006-15). 


\section{REFERENCES}

[1] G.A. Lane, Solar Heat Storage: Latent Heat Material, Volume I, first ed., CRC Press, Boca Raton, 1983.

[2] G.A. Lane, Solar Heat Storage: Latent Heat Material, Volume II, first ed., CRC Press, Boca Raton, 1986.

[3] H. Mehling, L.F. Cabeza, Heat and Cold Storage with PCM: an Up to Date Introduction into Basics and Applications, first ed., Springer, Berlin, 2008.

[4] P. Schossig, H-M. Henning, S. Gschwander, T. Haussmann, Micro-encapsulated Phase-Change Materials Integrated into Construction Materials, Sol. Energ. Mat. Sol. Cells 89 (2005) 297-306.

[5] L.F. Cabeza, C. Castellón, M. Nogués, M. Medrano, R. Leppers, O. Zubillaga, Use of Microencapsulated PCM in Concrete Walls for Energy Savings, Energ. Buildings 39 (2007) 113-119.

[6] A.M. Khudhair, M.M. Farid, A Review on Energy Conservation in Building Applications with Thermal Storage by Latent Heat Using Phase Change Materials, Energ. Convers. Manage. 45 (2004) 263-275.

[7] N. Sarier, E. Onder, The Manufacture of Microencapsulated Phase Change Materials Suitable for the Design of Thermally Enhanced Fabrics, Thermochim. Acta 452 (2007) 149-160.

[8] J.S. Cho, A. Kwon, C.G. Cho, Microencapsulation of Octadecane as a PhaseChange Material by Interfacial Polymerization in an Emulsion System, Colloid Polym. Sci. 280 (2002) 260-266.

[9] L. Sánchez, E. Lacasa, M. Carmona, J.F. Rodríguez, P. Sánchez, Applying an Experimental Design to Improve the Characteristics of Microcapsules Containing Phase Change Materials for Fabric Uses, Ind. Eng. Chem. Res. 47 (23) (2008) 9783-9790. 
[10] L. Ventolà, M.A. Cuevas-Diarte, T. Calvet, D. Mondieig, New Materials for Thermal Protection and Energy Storage, Mater. Techn. 20 (4) (2005) 193-196.

[11] L. Xing, L. Hongyan, W. Shujun, Z. Lu, C. Hua, Preparation and Thermal Properties of Form Stable Paraffin Phase Change Material Encapsulation, Energ. Convers. Manage. 47 (2006) 2515-2522.

[12] M.N.A. Hawlader, M.S. Uddin, M.M. Khin, Microencapsulated PCM ThermalEnergy Storage System, Appl. Energy 74 (2003) 195-202.

[13] S. Krishnan, A.C. Kshirsagar, R.S. Singhal, The Use of Gum Arabic and Modified Starch in the Microencapsulation of a Food Flavoring Agent, Carb. Polym. 62 (2005) 309-315.

[14] K. Kaygusuz, C. Alkan, A. Sari, O. Uzun, Encapsulated Fatty Acids in an Acrylic Resin as Shape-stabilized Phase Change Materials for Latent Heat Thermal Energy Storage, Energ. Sources, Part A 30 (2008) 1050-1059.

[15] D. Saihi, I. Vroman, S. Giraud, S. Bourbigot, Microencapsulation of Ammonium Phosphate with a Polyurethane Shell. Part I: Coacervation Technique, React. Funct. Polym. 64 (2005) 127-138.

[16] D. Saihi, I. Vroman, S. Giraud, S. Bourbigot, Microencapsulation of Ammonium Phosphate with a Polyuretane Shell. Part II: Interfacial Polymerization Technique, React. Funct. Polym. 66 (2006) 1118-1125.

[17] O. Pascu, R. Garcia-Valls, M. Giamberini, Interfacial Polymerization of an Epoxy Resin and Carboxilic Acids for the Synthesis of Microcapsules, Polym. Int. 57 (2008) 995-1006.

[18] C. Liang, X. Lingling, S. Hongbo, Z. Zhibin, Microencapsulation of Butyl Stearate as a Phase Change Material by Interfacial Polycondensation in a Polyurea System, Energ. Convers. Manage. 50 (2009) 723-729. 
[19] J.P. Wang, X.P. Zhao, H.L. Guo, Q. Zheng, Preparation of Microcapsules

Containing Two-Phase Core Materials, Langmuir 20 (2006) 10845-10850.

[20] G. Sun, Z. Zhang, Mechanical Strength of Microcapsules Made of Different Wall Materials, Int. J. Pharm. 242 (2002) 307-311.

[21] J. Su, L. Wang, L. Ren, Fabrication and Thermal Properties of MicroPCMs: Used Melamine-Formaldehyde Resin as Shell Material, J. Appl. Polym. Sci. 101 (2006) 15221528.

[22] J.F. Su, L.X. Wang, L. Ren, Preparation and Characterization Double-MF Shell MicroPCMs Used in Buiding Materials, J. Appl. Polym. Sci. 97 (2005) 1755-1762.

[23] J. Su, L. Ren, L. Wang, Preparation and Mechanical Properties of Thermal Energy Storage Microcapsules, Colloid Polym. Sci. 284 (2005) 224-228.

[24] G. Sun, Z. Zhang, Mechanical Properties of Melamine-Formaldehyde Microcapsules J. Microencapsulation 18 (5) (2001) 593-602.

[25] H. Zhang, X. Wang, Fabrication and Performances of Microencapsulated Phase Change Materials Based on n-octadecane Core and Resorcinol-Modified MelamineFormaldehyde Shell, Colloid Surf. A: Phys. Eng. Aspects. 332 (2009) 129-138.

[26] J.P. Wang, X.X. Zhang, X.C. Wang, Preparation of Macro-capsules Containing Shape-Stabilized Phase Change Materials and Description of Permeation Kinetics of its Wall, Energ. Convers. Manage. 50 (2009) 2802-2809.

[27] X.X. Zhang, X.M. Tao, K.I. Yick, X.C. Wang, Structure and Thermal Stability of Microencapsulated Phase-Change Materials, Colloid Polym. Sci. 282 (2004) 330-336.

[28] Rubitherm Technologies GmbH, Berlin. http://www.rubitherm.com/. Reference last accessed on 07/01/2010. 
[29] D. Mondieig, F. Rajabalee, V. Metivaud, H.A.J. Oonk, M.A. Cuevas-Diarte, nAlkane Binary Molecular Alloys, Chem. Mater. 16 (2004) 786-798.

[30] C. Alkan, A. Sari, A. Karaipekli, O. Uzun, Preparation, Characterization and Thermal Properties of Microencapsulated Phase Change Material for Thermal Energy Storage, Sol. Energy Mat. Sol. Cells 93 (2009) 143-147.

[31] BASF AG. Ludwigshaven, Germany. http://www.micronal.de/. Reference last accessed on 11/01/2010. 


\section{LEGENDS}

Figure 1. FE-SEM Images of microcapsules isolated from the matrix. a) Microcapsules obtained by the G/AG method; b) Microcapsules obtained by the AA/AG method; c) Nanocapsules obtained by the AA/AG method. The sample was subjected to a freezedrying process.

Figure 2. TOM Images of microcapsules obtained by the G/AG method. a) $301.7 \mathrm{~K}$ (room temperature); b) $273 \mathrm{~K}$; c) $299 \mathrm{~K}$; d) $308 \mathrm{~K}$.

Figure 3. Particle size distribution for the microcapsules synthesized by the G/AG method.

Figure 4. Particle size distribution for the microcapsules synthesized by the SG/AG method.

Figure 5. Particle size distribution for the microcapsules synthesized by the AA/AG method.

Figure 6. Particle size distribution for the nanocapsules synthesized by the AA/AG method.

Table 1. DSC data for free PCM and microencapsulated PCM

Figure 7. Comparison of the DSC thermograms for the free PCM and the microencapsulated one. a) Free PCM); b) Microencapsulated PCM with the AA/AG method; c) Microencapsulated PCM with the SG/AG method

Figure 8. TGA for the free PCM and the microencapsulated one. a) Free PCM (one step); b) Microencapsulated PCM with the SG/AG method (four steps); c) Microencapsulated PCM with the AA/AG method (four steps). Broken lines correspond to the DTGs (Derivatives of the Thermal Analysis). a') TG derivative from a; b') TG derivative from b; c') TG derivative from c. 
Table 2. TGA data for free PCM and microencapsulated PCM (by AA/AG and SG/AG methods)

Figure 1
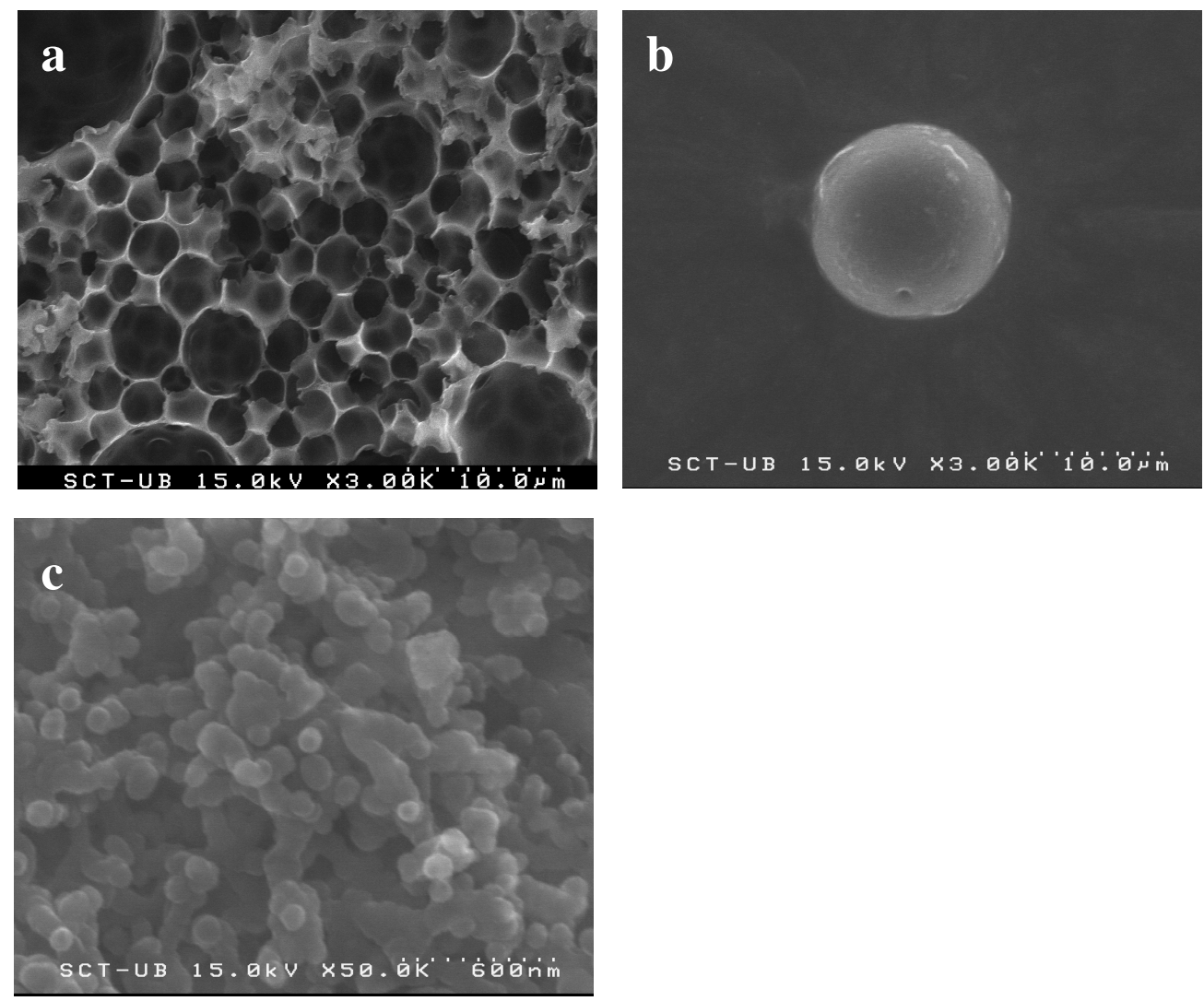
Figure 2
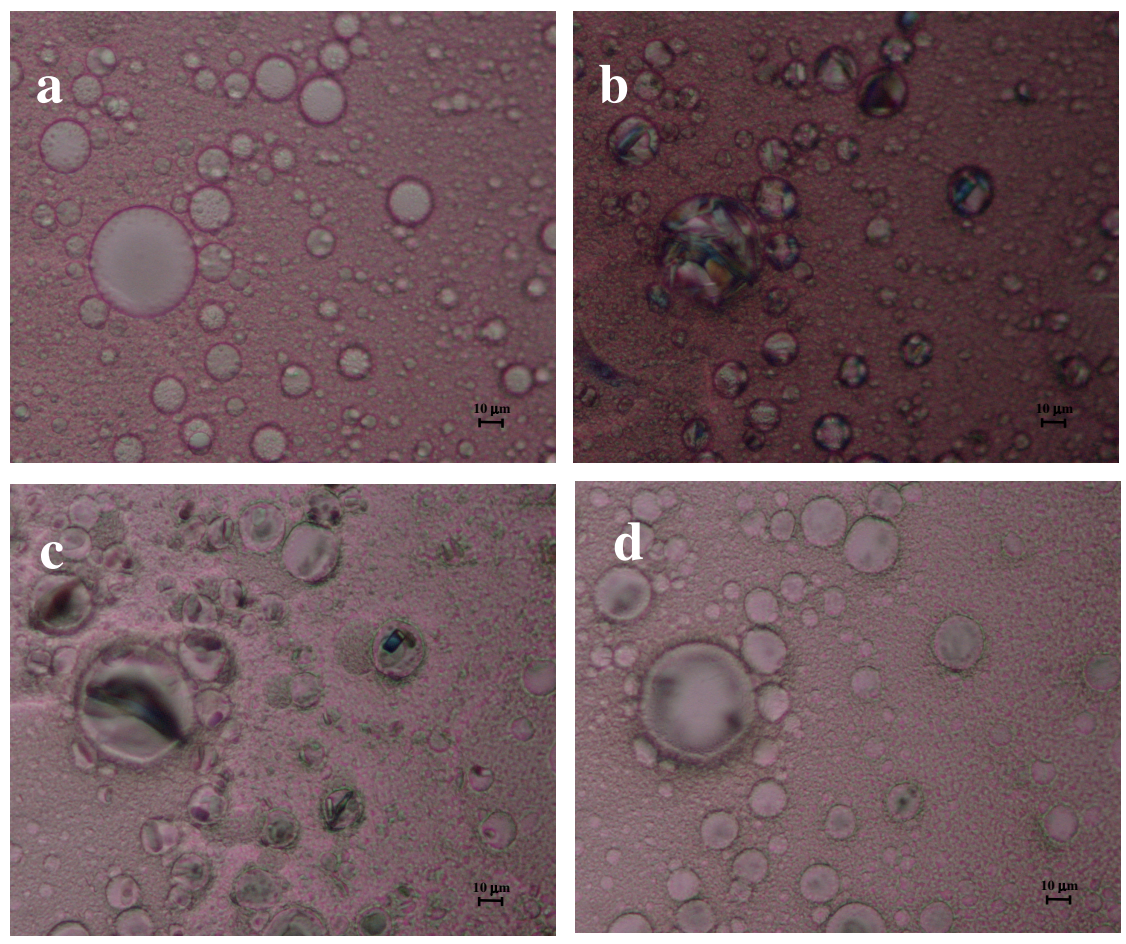

Figure 3

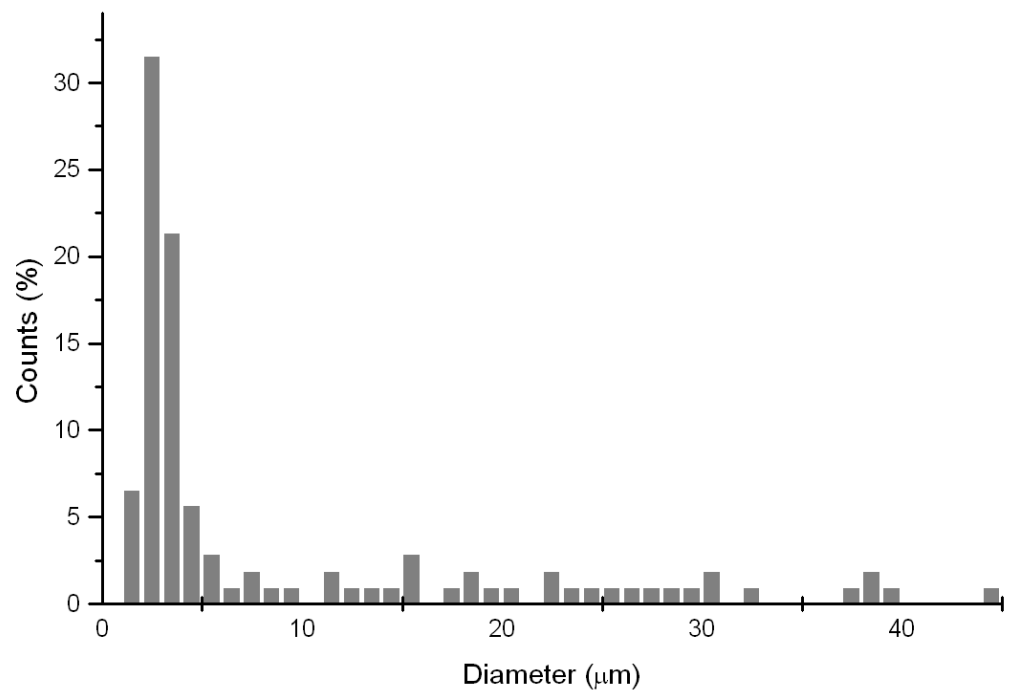


Figure 4

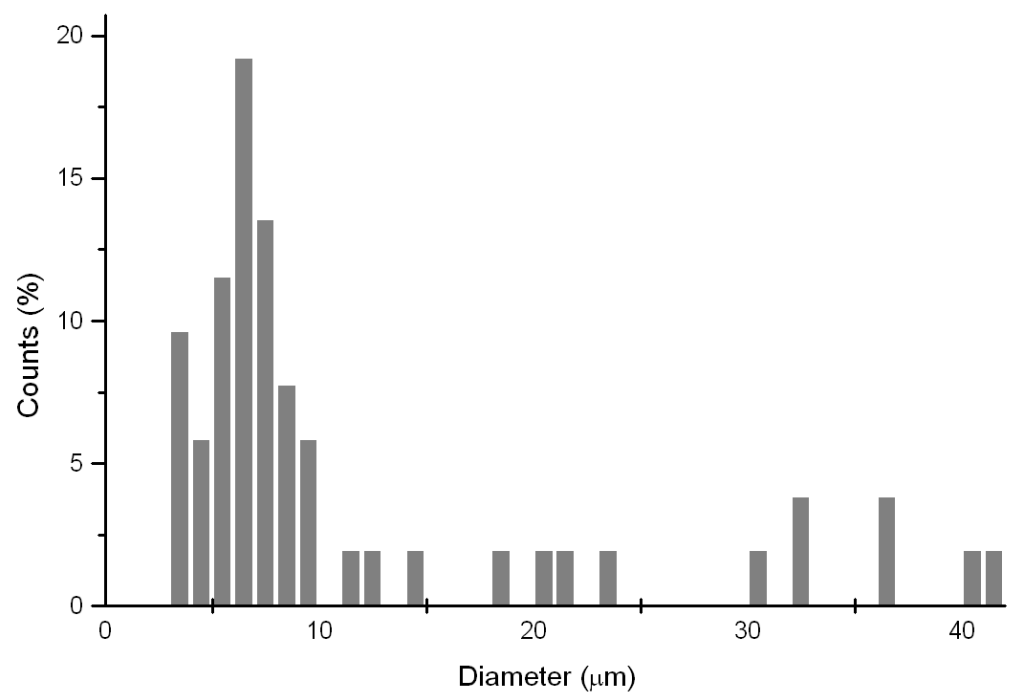

Figure 5

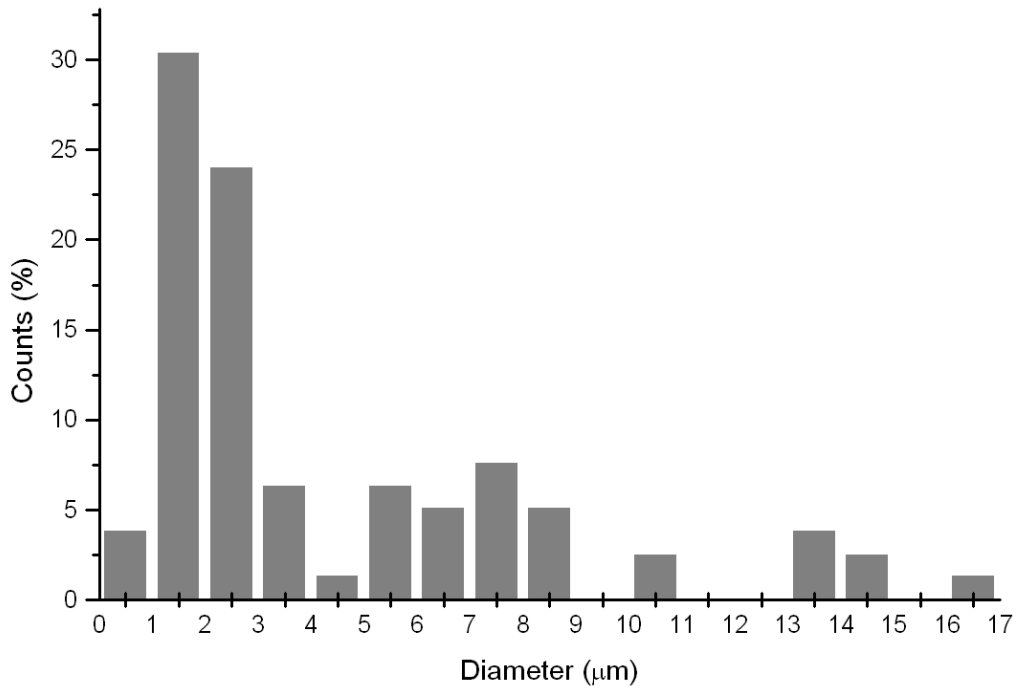


Figure 6

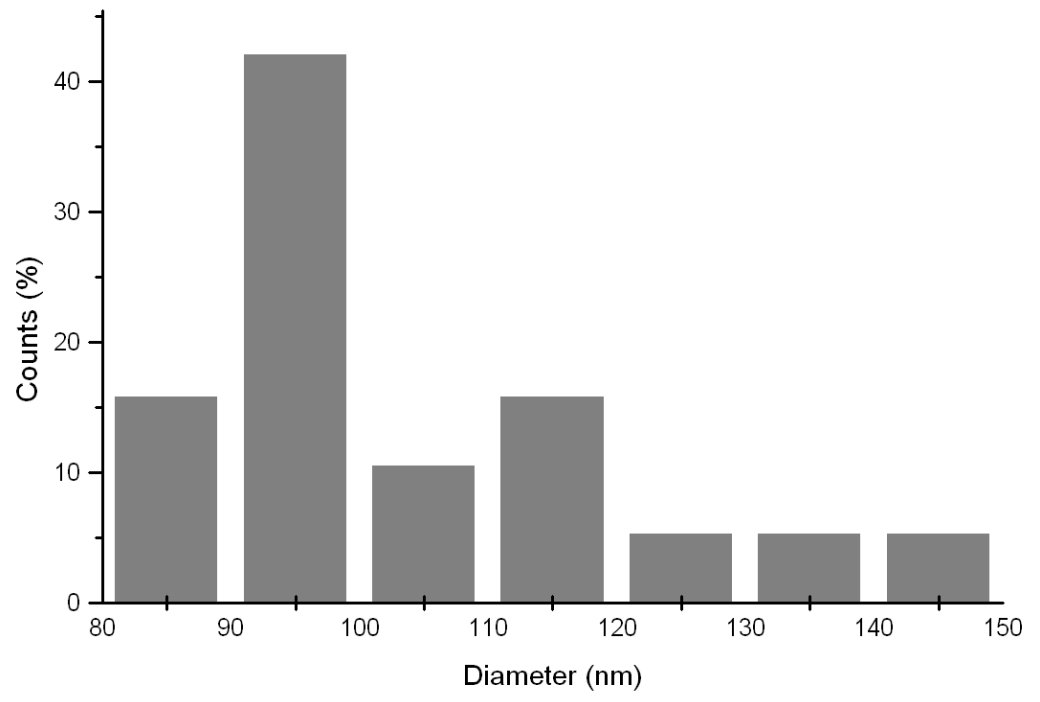

Figure 7

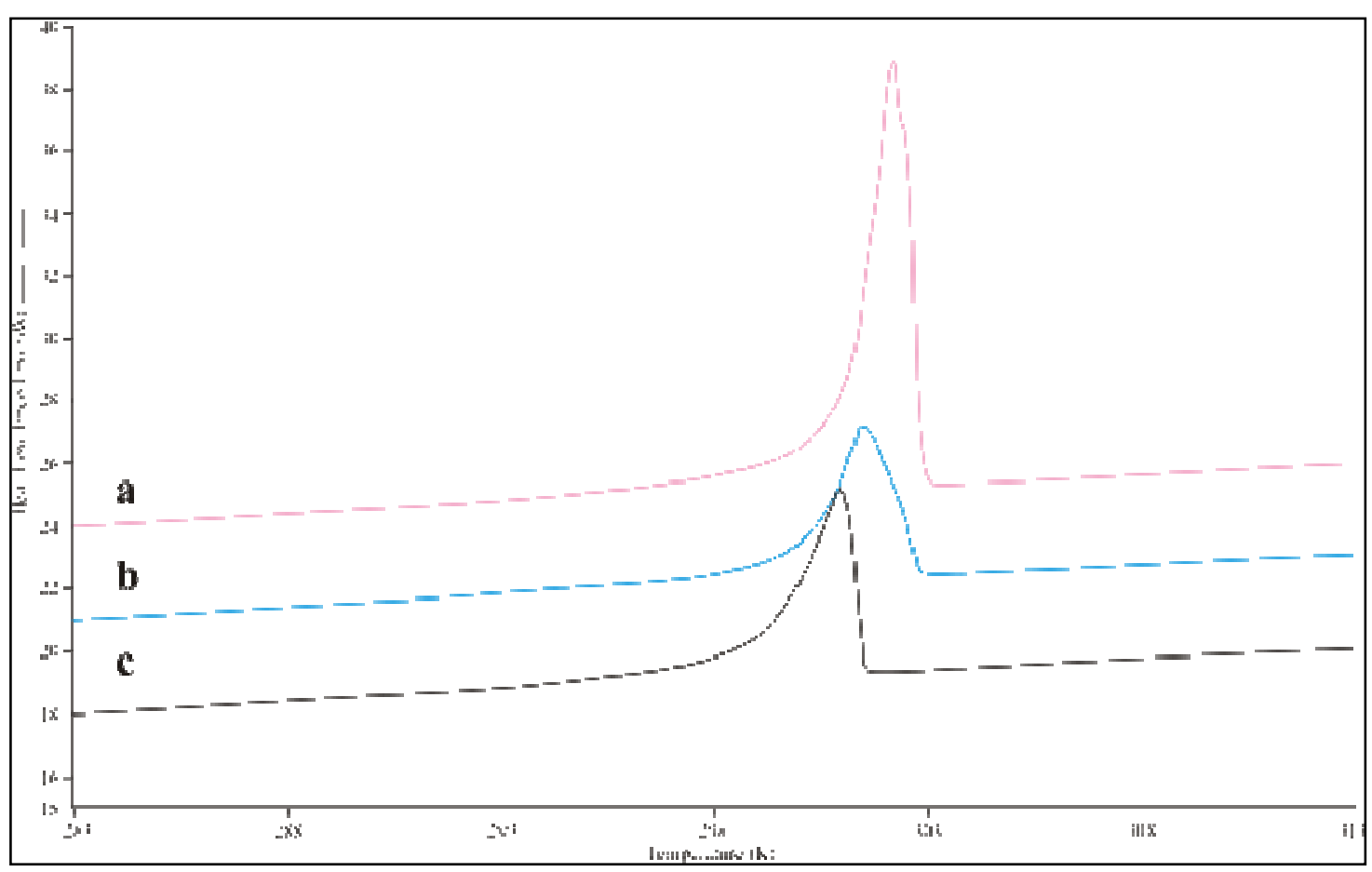


Figure 8

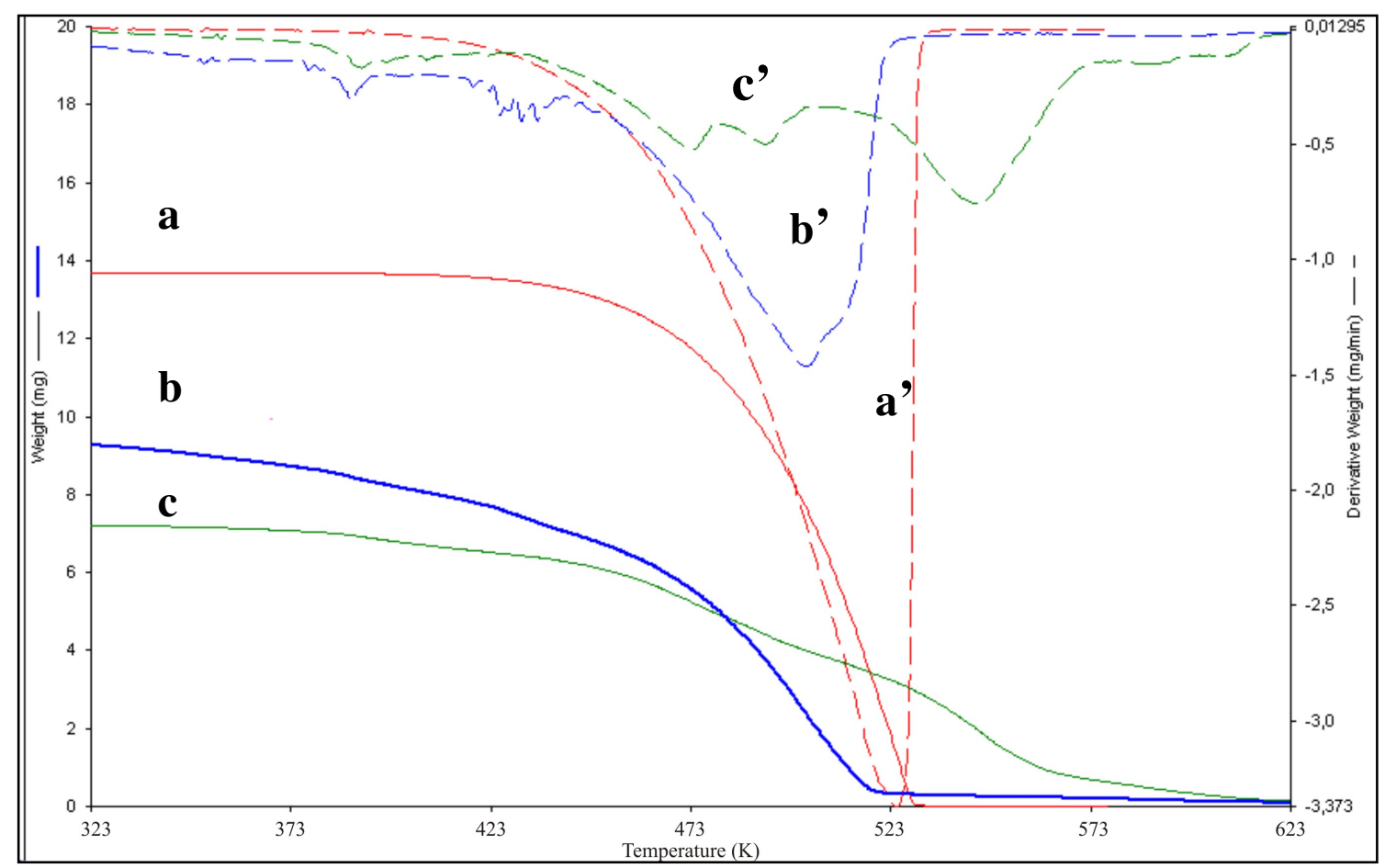

Table 1

\begin{tabular}{|l|l|l|l|}
\hline & $\mathbf{T}_{\text {onset }}(\mathbf{K})$ & $\mathbf{T}_{\text {end }}(\mathbf{K})$ & $\Delta \mathbf{H}\left(\mathbf{J}^{-\mathbf{g}^{-1}}\right)$ \\
\hline Free PCM & $301.0 \pm 0.6$ & $303.1 \pm 0.6$ & $162 \pm 8$ \\
\hline $\begin{array}{l}\text { Microencapsulated PCM } \\
\text { (SG/AG) }\end{array}$ & $298.3 \pm 0.4$ & $301.3 \pm 0.4$ & $79 \pm 10$ \\
\hline $\begin{array}{l}\text { Microencapsulated PCM } \\
\text { (AA/AG method) }\end{array}$ & $299.5 \pm 0.5$ & $302.5 \pm 0.8$ & $78 \pm 11$ \\
\hline
\end{tabular}


Table 2

\begin{tabular}{|c|c|}
\hline Degradation interval (K) & Percent mass loss $(\%)$ \\
\hline \multicolumn{2}{|l|}{ Free PCM } \\
\hline 392.3- 535.9 & 99.8 \\
\hline \multicolumn{2}{|c|}{ MEPCM (SG/AG method) } \\
\hline 323-359.3 (step 1: solvent loss) & 4.0 \\
\hline 359.3-394.5 (step 2: solvent loss) & 6.4 \\
\hline 394.5-440.1 (step 3:solvent loss) & 12.8 \\
\hline $\begin{array}{l}\text { 440.1-527.1 (step 4: microcapsules break and } \\
\text { components degradation) }\end{array}$ & 72.1 \\
\hline \multicolumn{2}{|c|}{ MEPCM (AA/AG method) } \\
\hline 322.3-415.5 (step 1: solvent loss: $\mathrm{H}_{2} \mathrm{O}$ and ether) & 8.7 \\
\hline 415.5-504.7 (step 2: microcapsules degradation) & 37.3 \\
\hline 504.7-577.6 (step 3: components decomposition) & 45.3 \\
\hline 577.6-623.1 (step 4: carbonization) & 6.4 \\
\hline
\end{tabular}

